\title{
Wetting Behavior of Mixtures of Water and Nonionic Polyoxyethylene Alcohol
}

\author{
Chih-Kang Wu and Li-Jen Chen* \\ Department of Chemical Engineering, National Taiwan University, Taipei, \\ Taiwan 10617, Republic of China
}

Received March 15, 2005. In Final Form: May 12, 2005

\begin{abstract}
Five binary water $+\mathrm{C}_{4} \mathrm{E}_{j}$ mixtures, water $+n-\mathrm{C}_{4} \mathrm{E}_{0}$, water $+2-\mathrm{C}_{4} \mathrm{E}_{0}$, water + iso- $\mathrm{C}_{4} \mathrm{E}_{0}$, water $+n-\mathrm{C}_{4} \mathrm{E}_{1}$, and water + iso- $\mathrm{C}_{4} \mathrm{E}_{1}$, were chosen to perform the surface/interfacial tension measurements over the experimental temperature range from 10 to $85^{\circ} \mathrm{C}$ at the normal pressure by using a homemade pendent drop/bubble tensiometer. The symbol $\mathrm{C}_{i} \mathrm{E}_{j}$ is the abbreviation of a nonionic polyoxyethylene alcohol $\mathrm{C}_{i} \mathrm{H}_{2 i+1}\left(\mathrm{OCH}_{2} \mathrm{CH}_{2}\right)_{j} \mathrm{OH}$. The wetting behavior of the $\mathrm{C}_{i} \mathrm{E}_{j}$-rich phase at the interface separating gas and the aqueous phase is systematically examined according to the wetting coefficient resulting from the experimental data of surface/interfacial tensions measurements. For those systems with a lower critical solution temperature, for example, water $+n-\mathrm{C}_{6} \mathrm{E}_{2}$, water $+n-\mathrm{C}_{4} \mathrm{E}_{1}$, and water + iso- $\mathrm{C}_{4} \mathrm{E}_{1}$, a wetting transition from partial wetting to nonwetting is always observed when the system is brought to close to its lower critical solution temperature. On the other hand, to start with a partial wetting $\mathrm{C}_{i} \mathrm{E}_{j}$-rich phase, a wetting transition from partial wetting to complete wetting is always observed when the system is driven to approach its upper critical solution temperature. The effect of hydrophobicity of $\mathrm{C}_{i} \mathrm{E}_{j}$ on the wetting behavior of the $\mathrm{C}_{i} \mathrm{E}_{j}$-rich phase at the interface separating gas and the aqueous phase was carefully investigated by using five sets of mixtures: (1) water $+n-\mathrm{C}_{4} \mathrm{E}_{0}$, water $+n-\mathrm{C}_{5} \mathrm{E}_{0}$, and water $+n-\mathrm{C}_{6} \mathrm{E}_{0} ;(2)$ water $+2-\mathrm{C}_{4} \mathrm{E}_{0}$ and water $+2-\mathrm{C}_{5} \mathrm{E}_{0}$; (3) water $+2-\mathrm{C}_{4} \mathrm{E}_{0}$ and water $+n-\mathrm{C}_{4} \mathrm{E}_{0}$; (4) water $+n-\mathrm{C}_{4} \mathrm{E}_{1}$, water $+n-\mathrm{C}_{5} \mathrm{E}_{1}$, and water $+n-\mathrm{C}_{6} \mathrm{E}_{1} ;(5)$ water $+n-\mathrm{C}_{4} \mathrm{E}_{0}$ and water $+n-\mathrm{C}_{4} \mathrm{E}_{1}$. The $\mathrm{C}_{i} \mathrm{E}_{j}$-rich phase would tend to drive away from complete wetting (or nonwetting) to partial wetting with an increase in the hydrophobicity of $\mathrm{C}_{i} \mathrm{E}_{j}$ in the binary water $+\mathrm{C}_{i} \mathrm{E}_{j}$ system. All the wetting behavior observed in the water $+\mathrm{C}_{i} \mathrm{E}_{j}$ mixtures is consistent with the prediction of the critical point wetting theory of Cahn.
\end{abstract}

\section{Introduction}

It is well-understood that water and oil are practically almost insoluble in each other. However, addition of a small amount of surfactant to the mixture of water and oil would substantially enhance the mutual solubility of water and oil. Within a certain temperature range, the ternary water + oil + surfactant system may separate into three coexisting liquid phases, namely, an aqueous (lower) phase, an oil-rich (upper) phase, and a surfactantrich (middle) phase. The wetting behavior of the $\mathrm{C}_{i} \mathrm{E}_{j}$-rich phase at the interface separating the oil-rich and aqueous phases in ternary water + oil $+\mathrm{C}_{i} \mathrm{E}_{j}$ mixtures had been extensively and systematically studied due to its importance in many industrial applications. ${ }^{1-13}$ The symbol $\mathrm{C}_{i} \mathrm{E}_{j}$ is the abbreviation of a nonionic surfactant polyoxyethylene alcohol $\mathrm{C}_{i} \mathrm{H}_{2 i+1}\left(\mathrm{OCH}_{2} \mathrm{CH}_{2}\right)_{j} \mathrm{OH}$.

The most intriguing phenomenon was observed in the water + tetradecane $+\mathrm{C}_{6} \mathrm{E}_{2}$ system: ${ }^{6}$ that the middle $\mathrm{C}_{6} \mathrm{E}_{2^{-}}$

* Corresponding author. E-mail: ljchen@ntu.edu.tw.

(1) Kahlweit, M.; Busse, G. J. Chem. Phys. 1989, 15, 1339

(2) Chen, L.-J.; Jeng, J.-F.; Robert, M.; Shukla, K. P. Phys. Rev. A 1990, 42,4716 .

(3) Bonkhoff, K.; Hirtz, A.; Findenegg, G. H. Physica A 1991, 172, 174.

(4) Hirtz, A.; Bonkhoff, K.; Findenegg, G. H. Adv. Colloid Interface Sci. 1993, 44, 241.

(5) Aratono, M.; Kahlweit, M. J. Chem. Phys. 1991, 95, 8578.

(6) Chen, L.-J.; Yan, W.-J. J. Chem. Phys. 1993, 98, 4830.

(7) Chen, L.-J.; Yan, W.-J.; Hsu, M.-C.; Tyan, D.-L. J. Phys. Chem. 1994, 98,1910

(8) Chen, L.-J.; Lin, S.-Y.; Xyu, J.-W. J. Chem. Phys. 1996, 101, 225

(9) Kahlweit, M.; Busse, G. J. Phys. Chem. B 2000, 104, 4939.

(10) Chen, L.-J.; Chiu, C.-D.; Shau, F.-S.; Cheng, W.-J.; Wu, J.-G,. J. Phys. Chem. B 2002, 106, 12782.

(11) Chen, L.-J.; Hsu, M.-C. J. Chem. Phys. 1992, 97, 690.

(12) Chen, L.-J.; Hsu. M.-C.; Lin, S.-T.; Yang, S.-Y. J. Phys. Chem. 1995, $99,4687$.

(13) Yeh, M.-C.; Chen, L.-J. J. Chem. Phys. 2001, 115, 8575. rich phase would undergo a sequence of wetting transitions, nonwetting $\rightarrow$ partial wetting $\rightarrow$ complete wetting, along with increasing temperature. This observation verifies the suggestion that the wetting behavior can be related to the temperature dependence of amphiphilicity of a surfactant. ${ }^{1}$

Several experimental approaches including direct eye observation, ${ }^{2,9}$ the contact angle measurement, ${ }^{5,6,8}$ and the surface/interfacial tension measurement $\mathrm{t}^{3,4,6,8-10}$ were applied to investigate the wetting behavior of the middle amphiphile-rich phase at the oil-water interface in ternary water + oil $+\mathrm{C}_{i} \mathrm{E}_{j}$ mixtures. It was found that these ternary systems can exhibit diverse wetting behaviors by simply varying system variables, such as temperature, ${ }^{2,5-10,13}$ oil chain length,,${ }^{7,9,10}$ amphiphilicity of a surfactant, ${ }^{5}$ and salinity. ${ }^{11,12}$

The binary water $+\mathrm{C}_{i} \mathrm{E}_{j}$ systems are also rich in wetting behavior, although these systems are relatively simple. Donahue and Bartell ${ }^{14}$ had reported the surface/interfacial tensions of several binary water + organic liquid mixtures, including some short- and medium-chain alcohols $\left(\mathrm{C}_{i} \mathrm{E}_{0}\right)$, only at $298.15 \mathrm{~K}$. The surface/interfacial tensions were related to the reciprocal solubility and used to determine the wetting behavior. It was found that the alcohol-rich phase exhibits partial wetting behavior at the air-water interface. It reveals that the surface tension of the aqueous phase is substantially lowered by the adsorbed alcohol molecules that prevent the spreading of the alcohol-rich phase over the water surface.

The wetting behavior of the water $+\mathrm{C}_{8} \mathrm{E}_{j}$ mixtures at 298.15 K was investigated by Kahlweit and Busse. ${ }^{1}$ These authors found that the contact angle $\theta$, as defined by Figure $1 b$, increases with increasing the number of oxyethylene

(14) Donahue, D. J.; Bartell, F. E. J. Phys. Chem. 1952, 56, 480. 


\begin{tabular}{|c|}
\hline$\alpha$ \\
\hline$\beta$ \\
\hline$\gamma$ \\
\hline
\end{tabular}

(a)

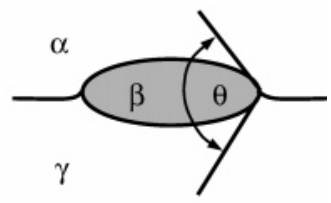

(b)

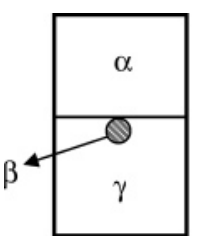

(a)

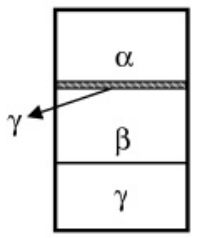

(a')

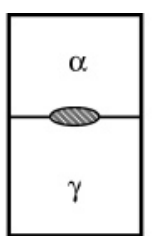

(b)

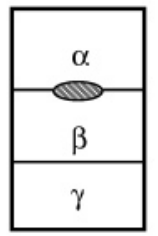

(b')

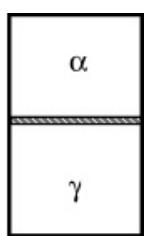

(c)

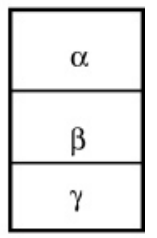

(c') the air-water interface near the lower critical solution temperature in the binary $\mathrm{C}_{i} \mathrm{E}_{j}+$ water mixtures. Aratono and co-workers ${ }^{15,16}$ had systematically studied the temperature dependence of surface and interfacial tensions of water + long-chain alcohols $(i=8-12)$. The crossover between surface tensions of both liquid phases and the intruding phenomena of the aqueous phase as a suspending lens at the air-alcohol interface were demonstrated. The interfacial phase transitions between the expanded and the condensed states were also manifested.

In our previous study, ${ }^{17}$ we demonstrated the molecular structure effect on the wetting behavior in the water + alcohol mixtures over the temperature range from 10 to $40{ }^{\circ} \mathrm{C}$ only. In this study, we assembled a new pendant bubble/drop tensiometer to extend our experimental temperature window up to $85^{\circ} \mathrm{C}$. In this work, five binary mixtures, (1) water $+n-\mathrm{C}_{4} \mathrm{E}_{0},(2)$ water $+2-\mathrm{C}_{4} \mathrm{E}_{0},(3)$ water $+i-\mathrm{C}_{4} \mathrm{E}_{0},(4)$ water $+n-\mathrm{C}_{4} \mathrm{E}_{1}$, and (5) water $+i-\mathrm{C}_{4} \mathrm{E}_{1}$, were employed to perform the surface/interfacial tensions. The wetting behavior, as well as the wetting transition, of the $\mathrm{C}_{i} \mathrm{E}_{j}$-rich phase at the air-water in the water $+\mathrm{C}_{i} \mathrm{E}_{j}$ mixtures is then determined by the wetting coefficient. In this study, the wetting behavior of the $\mathrm{C}_{i} \mathrm{E}_{j}$-rich phase at the air-water in the water $+\mathrm{C}_{i} \mathrm{E}_{j}$ mixtures is systematically examined. To start with a partial wetting $\mathrm{C}_{i} \mathrm{E}_{j}$-rich phase, a wetting transition must occur when the system is driven to approaching its critical end point, as predicted by the critical point wetting theory. ${ }^{18,19}$ In this study the occurrence of a wetting transition in the binary water + $\mathrm{C}_{i} \mathrm{E}_{j}$ system is directly related to its critical end point. It should be noted that some observations ${ }^{20-24}$ raise a question on the necessity of a wetting transition to occur along with leaving or approaching a critical end point of the system.

This paper is organized as follows. The definitions of the wetting behavior and the critical point wetting theory are illustrated in the next section. Then, the experimental details including a homemade pendant drop/bubble tensiometer and experimental procedures are described. The

(15) Aratono, M.; Toyomasu, T.; Shinoda, T.; Ikeda, N.; Takiue, T. Langmuir 1997, 13, 2158.

(16) Toyomasu, T.; Takiue, T.; Ikeda, N.; Aratono, M. Langmuir 1998, 14,7313 .

(17) Yeh, M.-C.; Lin, P.-C.; Chen, L.-J. J. Phys. Chem. B 2004, 108, 9955.

(18) Cahn, J. W. J. Chem. Phys. 1977, 66, 3667.

(19) Ebner, C.; Saam, W. F. Phys. Rev. Lett. 1977, 38, 1486.

(20) Ragil, K.; Bonn, D.; Broseta, D.; Meunier, J. J. Chem. Phys. 1996, 105,5160

(21) Ragil, K.; Meunier, J.; Broseta, D.; Indekeu, J. O.; Bonn, D. Phys. Rev. Lett. 1996, 77, 1532.

(22) Shahidzadeh, N.; Bonn, D.; Ragil, K.; Broseta, D.; Meunier, J. Phys. Rev. Lett. 1998, 80, 3992.

(23) Bertrand, E.; Dobbs, H.; Broseta, D.; Indekeu, J. O.; Bonn, D.; Meunier, J. Phys. Rev. Lett. 2000, 85, 1282.

(24) Dobbs, H. J. Chem. Phys. 2001, 114, 468.
Figure 2. Wetting behavior at a fluid-fluid interface: (a) a nonwetting $\beta$ phase at the $\alpha-\gamma$ interface; ( $\mathrm{a}^{\prime}$ ) a complete wetting $\gamma$ phase at the $\alpha-\beta$ interface; (b) a partial wetting $\beta$ phase at the $\alpha-\gamma$ interface; (b') a partial wetting $\gamma$ phase at the $\alpha-\beta$ interface; (c) a complete wetting $\beta$ phase at the $\alpha-\gamma$ interface; and ( $\left.\mathrm{c}^{\prime}\right)$ a thick layer of $\beta$ phase separating the $\alpha$ and $\gamma$ phases. The expected condition for only a small amount of the $\beta$ phase at the $\alpha-\gamma$ interface is shown in the upper row $(\mathrm{a}-\mathrm{c})$, and the condition for a substantial amount of the $\beta$ phase is shown in the lower row $\left(a^{\prime}-c^{\prime}\right)$. The thickness of the $\gamma$ phase wetting layer in $a^{\prime}$ is exaggerated for illustration.

experimental results of surface/interfacial tensions for five binary water $+\mathrm{C}_{4} \mathrm{E}_{j}$ mixtures are presented. The effect of hydrophobicity of $\mathrm{C}_{i} \mathrm{E}_{j}$ on the wetting behavior of the $\mathrm{C}_{i} \mathrm{E}_{j}$-rich phase at the air-water interface is discussed in detail. All the wetting transitions observed in this study are consistent with the prediction of the critical point wetting theory.

\section{Wetting Behavior and Critical Point Wetting Theory}

Three fluid phases, $\alpha, \beta$, and $\gamma$, are considered, in equilibrium under gravity, and the densities of these three phases are in the order $\rho_{\gamma}>\rho_{\beta}>\rho_{\alpha}$, as shown in Figure 1a. For systems of two liquid phases coexisting with air, the $\alpha, \beta$, and $\gamma$ phases stand for the air, upper liquid, and lower liquid phases, respectively. The wetting behavior of the middle $\beta$ phase can be easily realized by the wetting coefficient defined as $W=\left(\sigma_{\alpha \beta}-\sigma_{\alpha \gamma}\right) / \sigma_{\beta \gamma}$ and by the contact angle $\theta$ spanned by the $\alpha-\beta$ and the $\beta-\gamma$ interfaces, as shown in Figure 1b. The symbol $\sigma_{i j}$ stands for the interfacial tension of the interface separating $i$ and $j$ phases. Based on the wetting coefficient $W$ and the contact angle $\theta$, the wetting behavior can then be classified into three types, as illustrated in Figure 2.

(a) $W=1$ and $\theta=180^{\circ}$, a nonwetting $\beta$ phase at the $\alpha-\gamma$ interface, as shown in Figure 2a. While the system has a substantial amount of the $\beta$ phase, the $\alpha$ phase would exhibit complete wetting behavior at the $\beta-\gamma$ interface, as shown in Figure $2 \mathrm{a}^{\prime}$. In this case the Antonow rule ${ }^{25}$ is applied in the form $\sigma_{\alpha \beta}=\sigma_{\alpha \gamma}+\sigma_{\beta \gamma}$.

(b) $-1<W<1$ and $0^{\circ}<\theta<180^{\circ}$, a partial wetting $\beta$ phase at the $\alpha-\gamma$ interface, as shown in Figure 2b. The relationship between tensions is $\sigma_{\alpha \beta}+\sigma_{\beta \gamma}>\sigma_{\alpha \gamma}>\sigma_{\alpha \beta}-$ $\sigma_{\beta \gamma}$, which follows the Neumann inequality. ${ }^{26}$

(c) $W=-1$ and $\theta=0^{\circ}$, a complete wetting $\beta$ phase at the $\alpha-\gamma$ interface, as shown in Figure 2c. In this case the tensions obey the Antonow rule, ${ }^{25} \sigma_{\alpha \beta}+\sigma_{\beta \gamma}=\sigma_{\alpha \gamma}$.

The occurrence of a wetting transition has been successfully predicted by the theoretical works of $\mathrm{Cahn}^{18}$ and

(25) Antonow, G. N. J. Chim. Phys. 1907, 5, 372.

(26) Buff, F. P. Encycl. Phys. 1960, 10 (7), 298, 299. 


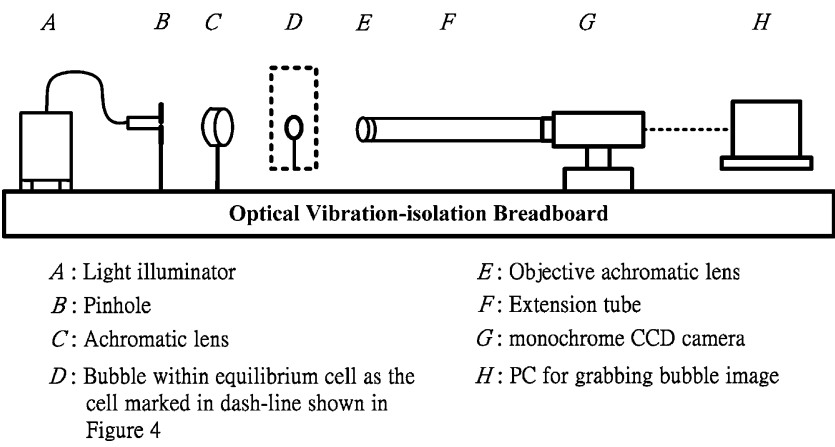

Figure 3. Schematic setup of the pendant bubble/drop tensiometry.

Ebner and Saam. ${ }^{19}$ When a three-phase system with a partial-wetting middle phase approaches a critical end point, the middle phase should completely wet (or does not wet) the interface between the upper and lower phases. In other words, as a multiphase system is brought close to a critical end point, these theoretical works predict that a transition must occur, for the middle phase, from partial wetting behavior to complete wetting (or nonwetting) behavior. That is a transition between partial wetting and complete wetting or between partial wetting and nonwetting. This is celebrated as a critical point wetting theory. Gompper and Schick ${ }^{27}$ had reviewed the theoretical works on the occurrence of wetting transitions in water + oil + surfactant mixtures.

In the vapor-liquid-liquid equilibrium binary system of methanol and cyclohexane, Moldover and Cahn ${ }^{29}$ observed the intriguing phenomenon of a thin layer of the denser methanol-rich $\gamma$ phase overcoming the gravitational field to intrude between the less dense cyclohexanerich $\beta$ phase and the vapor $\alpha$ phase, as illustrated in Figure $2 a^{\prime}$. These authors were able to induce a wetting transition from a $\gamma$ phase wetting layer to a lens suspended at the $\alpha-\beta$ interface, as illustrated in Figure $2 b^{\prime}$, by adding a small amount of water. The $\gamma$ phase wetting layer had also been observed and described in detail in our previous study. ${ }^{6,8}$ Such a wetting transition has been experimentally observed not only at vapor-liquid interfaces ${ }^{3,4,13,17,32}$ but also at liquid-liquid interface ${ }^{5-8,10-12}$ and at fluid-solid interfaces. ${ }^{35-39}$ We would like to refer the reader to an excellent review article by Bonn and Ross ${ }^{40}$ covering all details of the experimental works on wetting transitions.

\section{Experimental Section}

Materials. All the chemicals, $n$-butanol $\left(n-\mathrm{C}_{4} \mathrm{E}_{0},>99.5 \%\right)$, 2-butanol (2- $\left.\mathrm{C}_{4} \mathrm{E}_{0},>99 \%\right)$, 2-methyl-1-propanol (iso- $\mathrm{C}_{4} \mathrm{E}_{0},>99 \%$ ), and ethylene glycol monobutyl ether $\left(n-\mathrm{C}_{4} \mathrm{E}_{1}, 99 \%\right)$ were pur-

(27) Gompper, G.; Schick, M. In Phase Transitions and Critical Phenomena; Domb, C., Lebowitz, J. L., Eds.; Academic: New York, 1994; Vol. 16

(28) Schick, M. Ber. Bunsen-Ges. Phys. Chem. 1966, 100, 272.

(29) Moldover, M. R.; Cahn, J. W. Science 1980, 207, 1073.

(30) Schmidt, J. W.; Moldover, M. R. J. Chem. Phys. 1983, 79, 379

(31) Kahlweit, M.; Busse, G.; Haase, D.; Jen, J. Phys. Rev. A 1988 $38,1395$.

(32) Bonn, D.; Hellay, H.; Wegdam, G. H. Phys. Rev. Lett. 1992, 69 1975.

(33) Carrillo, E.; Talanquer, V.; Costas, M. J. Phys. Chem. 1996, 100 , 5888 .

(34) Ross, D.; Bonn, D.; Posazhennikova, A. I.; Indekeu, J. O.; Meunier, J. Phys. Rev. Lett. 2001, 87, 176103.

(35) Aarts, D. G. A. L.; van der Wiel, J. H.; Lekkerkerker, H. N. W. J. Phys.: Condens. Matter 2003, 15, S245.

(36) Wijting, W. K.; Besseling, N. A. M.; Cohen Stuart, M. A. Phys. Rev. Lett. 2003, 90, 196101.

(37) Wijting, W. K.; Besseling, N. A. M.; Cohen Stuart, M. A. J. Phys. Chem. B 2003, 107, 10565.

(38) Aarts, D. G. A. L.; Lekkerkerker, H. N. W. J. Phys.: Condens. Matter 2004, 16, S4231.

(39) Aarts, D. G. A. L. J. Phys. Chem. B 2005, 109, 7407. chased from Merck Chemical Co. and used as received. Ethylene glycol monoisobutyl ether (iso- $\mathrm{C}_{4} \mathrm{E}_{1}, 98 \%$ ) was a product of Tokyo Kasei Kogyo Co., Ltd., and was fractionally distilled under reduced pressure until a purity of $>99.5 \%$, as determined by gas chromatography, was attained. Water was purified by doubledistillation and then followed by a PURELAB (Maxima, Elga) purification system with the resistivity always better than 18.2 $\mathrm{M} \Omega \cdot \mathrm{cm}$.

Pendant Bubble/Drop Tensiometry. A homemade pendant bubble/drop tensiometer was used to measure the interfacial tension between two coexisting liquid phases and the surface tensions of both liquid phases against air. The schematic diagram of the tensiometer is shown in Figure 3. This device was mainly composed of a parallel light generator including a light source (model 190, fiber optical illuminator, Dolan-Jenner), a diffuser, a pinhole, an achromatic lens, a solid-state monochrome CCD camera (XC-ST70, Sony), a computer, and an image frame grabber (DT3155 MACH Series, Data Translation). The air bubble (or liquid drop) image on the active area of the camera was magnified approximately 1 (or 1.8) times for surface (or interfacial) tension measurement. The frame grabber digitized an image into $640 \times$ 480 pixels with 8 bits resolution of 256 gray levels. The air bubble (or liquid drop) forming system was composed of a precision syringe pump (model 100DM, ISCO Inc.) and stainless steel needles. Two needles (Hamilton Co.) of different diameters: gauge no. $17(1.07 \mathrm{~mm}$, i.d.; $1.47 \mathrm{~mm}$, o.d.) and gauge no. $27(0.21 \mathrm{~mm}$, i.d.; $0.41 \mathrm{~mm}$, o.d.) were equipped at the bottom of the equilibrium cell respectively for surface and interfacial tension measurement. The equilibrium cell was the glass liquid level gage (series 20) of Jerguson Gage \& Valve Co. The sample mixture was held in the equilibrium cell, which was housed in a thermostat (TV4000, Tamson Labovisco, Holland). The temperature stability of the thermostat was better than $\pm 0.05 \mathrm{~K}$. The detail setup of the equilibrium cell and the piping is schematically illustrated in Figure 4.

Procedures. The equilibrium cell and all the pipelines were vacuumed by vacuum pump (GCD-050XA, Sinku Kiko Co., Ltd., Japan). About $100 \mathrm{~mL}$ of degassed sample mixture with a proper composition was automatically sucked into the equilibrium cell through the pipe line by pressure difference. The inert gas (helium of $99.99 \%$ purity) was then injected into the system to maintain the system at the normal pressure, as indicated by a digital pressure gauge (DPI280/PDCR912, Druck Ltd.). The liquid sample in the equilibrium cell was circulated by the liquid pump (LDC analytical minipump) for at least $2 \mathrm{~h}$ to ensure thorough mixing. The equilibration was established for several hours up to 1 day. When the equilibrium was determined, both the liquid phases in the equilibrium cell were clear and transparent with sharp and mirrorlike interfaces.

The precision syringe pump (model 100DM, ISCO) was applied to drive the upper fluid phase through the pipe line to form an air bubble (or liquid drop) at the selected needle in the lower liquid phase. For each tension, at least 10 different air bubbles (or liquid drops) were formed. For each air bubble (or liquid drop), at least 10 images were taken for image analysis. An edge detection program was similar to that of the previous work ${ }^{41-43}$ to determine the bubble/drop profile from a digitized image. Once an air bubble (or a liquid drop) profile was digitized and allocated, the selected-plane method was applied to determine the surface (or interfacial) tension by fitting the profile to the Young-Laplace equation. ${ }^{41-43}$ Density for each liquid phase was measured by using a vibrating-tube densiometer (DAM 60/512, Anton Paar, Austria). The experimental uncertainty of the surface/interfacial tension measurements was better than $0.3 \%$

\section{Results and Discussion}

In this study, the surface/interfacial tensions were performed for five binary mixtures: water $+n-\mathrm{C}_{4} \mathrm{E}_{0}$, water

(40) Bonn, D.; Ross, D. Rep. Prog. Phys. 2001, 64, 1085.

(41) Yeh, M.-C.; Chen, L.-J.; Lin S.-Y.; Hsu, C.-T. J. Chin. Inst. Chem. Eng. 2001, 32, 109.

(42) Lin, S.-Y.; Chen, L.-J.; Xyu, J.-W.; Wang, W.-J. Langmuir 1995, 11,4159 .

(43) Lin, S.-Y.; Chen, L.-J.; Wang, W.-J.; Lin, L.-W. Colloids Surf., A 1996, 114, 31 . 


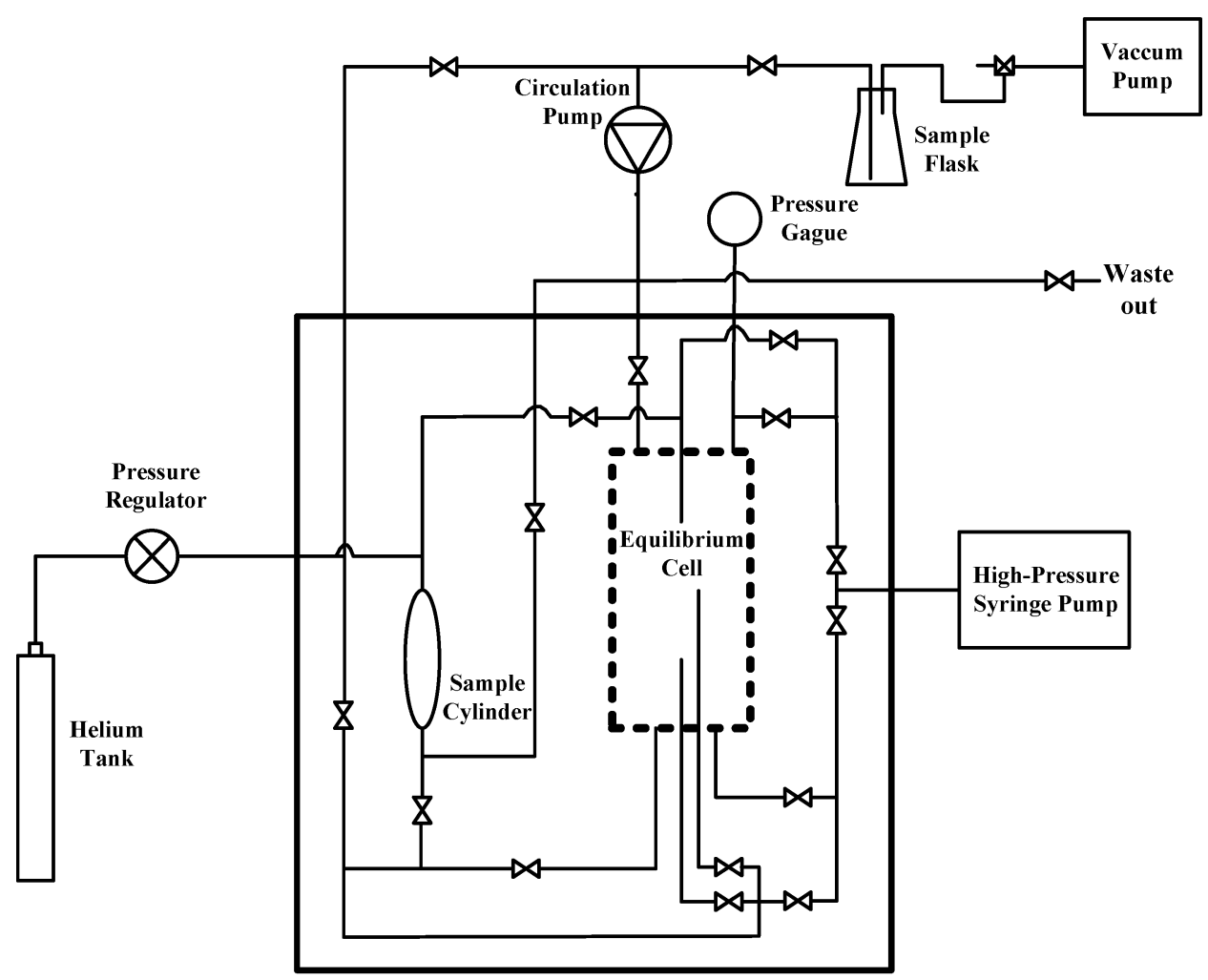

Thermostat (Tamson TV4000)

Figure 4. Schematic setup of the equilibrium cell and the bubble/drop forming system.

$+2-\mathrm{C}_{4} \mathrm{E}_{0}$, water + iso- $\mathrm{C}_{4} \mathrm{E}_{0}$, water $+n-\mathrm{C}_{4} \mathrm{E}_{1}$, and water + iso- $\mathrm{C}_{4} \mathrm{E}_{1}$ by the homemade pendant drop/bubble tensiometer. It is well-understood that three mixtures, water $+n-\mathrm{C}_{4} \mathrm{E}_{0}$, water $+2-\mathrm{C}_{4} \mathrm{E}_{0}$, and water + iso- $\mathrm{C}_{4} \mathrm{E}_{0}$, exhibit liquid-liquid equilibrium over the experimental temperature range $10-85^{\circ} \mathrm{C}$ at the normal pressure. ${ }^{44}$ The other two mixtures, water $+n-\mathrm{C}_{4} \mathrm{E}_{1}$ and water + iso- $\mathrm{C}_{4} \mathrm{E}_{1}$, exhibit their lower critical solution temperatures at 49 and 24.5 ${ }^{\circ} \mathrm{C}$, respectively. ${ }^{45,46}$ The $\alpha, \beta$, and $\gamma$ phases defined in Figure 2 correspond to the air, alcohol-rich, and aqueous phases, respectively, in these liquid-liquid equilibrium systems. The surface/interfacial tensions of these five mixtures were performed. Figure 5 illustrates the temperature dependence of the surface/interfacial tensions for these five water $+\mathrm{C}_{4} \mathrm{E}_{\mathrm{j}}$ systems. Then the wetting coefficient is further determined by the surface/interfacial tensions, as given in Figure 6 . The wetting behavior of the $\mathrm{C}_{4} \mathrm{E}_{j}$-rich phase at the interface separating air and the aqueous phase is then verified according to the wetting coefficient, as mentioned above.

Effect of Temperature on Wetting Behavior. It is interesting to observe that the wetting coefficient of the system $2-\mathrm{C}_{4} \mathrm{E}_{0}+$ water remains equal to -1 over the whole experimental temperature range, as shown in Figure 6. Thus, the alcohol-rich phase of the system $2-\mathrm{C}_{4} \mathrm{E}_{0}+$ water always exhibits complete wetting behavior at the surface of the aqueous phase. Note that the alcohol-rich phase of the other four systems exhibits a wetting transition at the interface separating air and the aqueous phase.

A wetting transition from partial wetting to complete wetting occurs in two systems $n-\mathrm{C}_{4} \mathrm{E}_{0}+$ water and iso$\mathrm{C}_{4} \mathrm{E}_{0}+$ water, when these systems are driven from low

(44) Sørensen, J. M.; Arlt, W. Liquid-Liquid Equilibrium Data Collection, Vol. 1, Binary Systems; DECHEMA Chemistry Data Series; DECHEMA: Frankfurt, Germany, 1979.

(45) Cox, H. L.; Cretcher, L. H. J. Am. Chem. Soc. 1926, 48, 451.

(46) Kim, K. Y.; Lim, K.-H. J. Chem. Eng. Data 2001, 46, 967. temperatures to high temperatures. As one can see in Figure 6, the wetting coefficient decreases with rising temperature and eventually goes to -1 (complete wetting behavior), where the wetting transition occurs. The wetting transition temperatures are 79.5 and $64.0{ }^{\circ} \mathrm{C}$ for respectively $n-\mathrm{C}_{4} \mathrm{E}_{0}+$ water and iso- $\mathrm{C}_{4} \mathrm{E}_{0}+$ water systems. It is well-understood that the upper critical solution temperatures of $n-\mathrm{C}_{4} \mathrm{E}_{0}+$ water and iso- $\mathrm{C}_{4} \mathrm{E}_{0}+$ water systems are 125 and $133{ }^{\circ} \mathrm{C},{ }^{45,46}$ respectively. To start with partial wetting behavior at low temperatures, indeed a wetting transition to complete wetting behavior occurs when the system is driven to approach its upper critical solution temperature, as predicted by Cahn. ${ }^{18}$ In our previous study, ${ }^{17}$ we also demonstrated that systematic trend of wetting behavior in the systems $n-\mathrm{C}_{5} \mathrm{E}_{0}+$ water and $n-\mathrm{C}_{6} \mathrm{E}_{0}+$ water up to $40{ }^{\circ} \mathrm{C}$. It is expected that these two systems should also exhibit a wetting transition from partial wetting to complete wetting when these systems are driven to further approach their upper critical solution temperatures.

On the other hand, a wetting transition from partial wetting to nonwetting occurs in the other two systems $n-\mathrm{C}_{4} \mathrm{E}_{1}+$ water and iso- $\mathrm{C}_{4} \mathrm{E}_{1}+$ water when these systems are driven from high temperatures to low temperatures. The wetting coefficient increases with decreasing temperature and eventually reaches unity (nonwetting behavior), where the wetting transition occurs, as shown in Figure 6. The wetting transition temperatures are 58.5 and $29.5{ }^{\circ} \mathrm{C}$ for respectively $n-\mathrm{C}_{4} \mathrm{E}_{1}+$ water and iso- $\mathrm{C}_{4} \mathrm{E}_{1}$ + water systems. It is well-understood that the lower critical solution temperatures of $n-\mathrm{C}_{4} \mathrm{E}_{1}+$ water and iso$\mathrm{C}_{4} \mathrm{E}_{1}+$ water systems are 49 and $25{ }^{\circ} \mathrm{C},{ }^{45,46}$ respectively. To start with partial wetting behavior, indeed a wetting transition to nonwetting behavior occurs when the system is driven from high temperatures to approach its lower critical solution temperature, consistent with the prediction of Cahn. ${ }^{18}$ In our previous study, ${ }^{17}$ we also demon- 

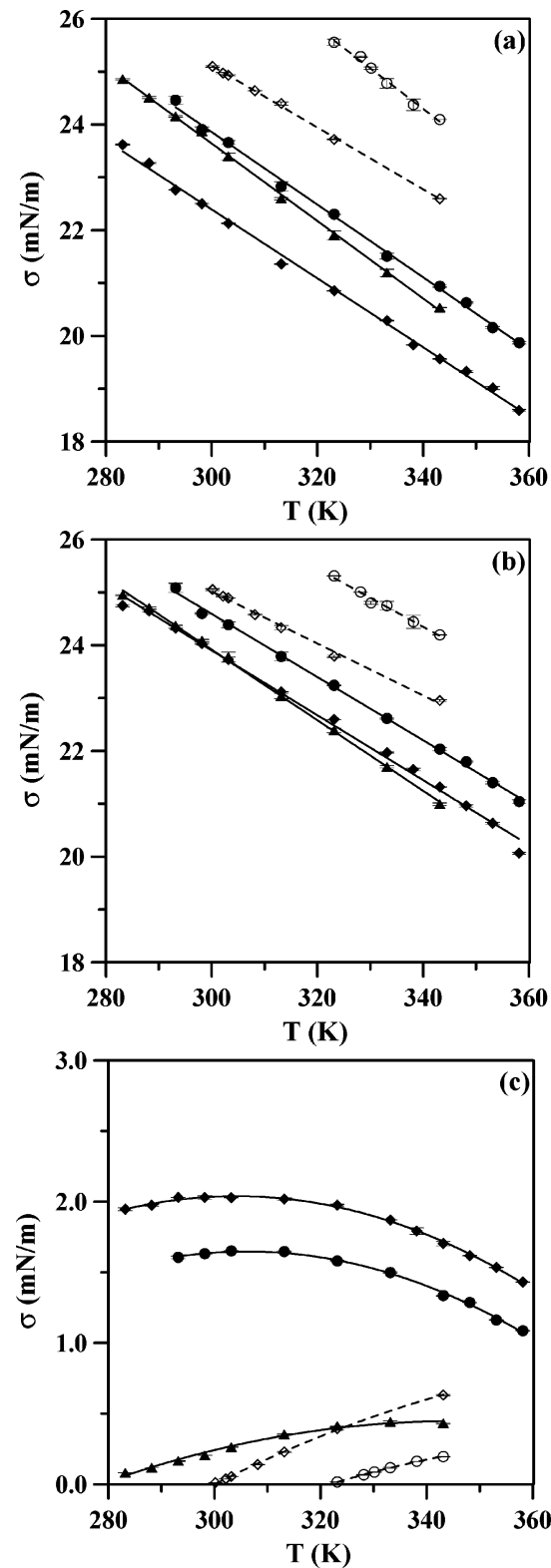

Figure 5. Variation of surface/interfacial tensions as a function of temperature for five water $+\mathrm{C}_{4} \mathrm{E}_{j}$ systems: (a) $\sigma_{\alpha \beta}$, the air$\mathrm{C}_{4} \mathrm{E}_{j}$-rich interface; (b) $\sigma_{\alpha \gamma}$, the air-aqueous interface; (c) $\sigma_{\beta \gamma}$, the $\mathrm{C}_{4} \mathrm{E}_{j}$-rich-aqueous interface. $n-\mathrm{C}_{4} \mathrm{E}_{0}(\bullet) ; 2-\mathrm{C}_{4} \mathrm{E}_{0}(\Delta)$; iso$\mathrm{C}_{4} \mathrm{E}_{0}(\diamond) ; n-\mathrm{C}_{4} \mathrm{E}_{1}(\mathrm{O}) ;$ iso- $\mathrm{C}_{4} \mathrm{E}_{1}(\diamond)$.

strated the systematic trend of wetting behavior in the systems $n-\mathrm{C}_{6} \mathrm{E}_{1}+$ water and $n-\mathrm{C}_{6} \mathrm{E}_{2}+$ water up to $40{ }^{\circ} \mathrm{C}$. The binary $n-\mathrm{C}_{6} \mathrm{E}_{2}+$ water system consistently exhibits a wetting transition from partial wetting to nonwetting when the system is driven from high temperatures to its lower critical solution temperature. It was found that the system $n-\mathrm{C}_{6} \mathrm{E}_{1}+$ water would not exhibit a wetting transition from partial wetting to nonwetting before the freezing point when the system temperature further decreases.

Effect of Hydrophobicity of $\mathrm{C}_{\mathrm{i}} \mathrm{E}_{\mathrm{j}}$ on Wetting Behavior Approaching the Upper Critical Solution Temperature. First, consider three isomeric $\mathrm{C}_{4} \mathrm{E}_{0}$ systems, $n-\mathrm{C}_{4} \mathrm{E}_{0}+$ water, $2-\mathrm{C}_{4} \mathrm{E}_{0}+$ water, and iso- $\mathrm{C}_{4} \mathrm{E}_{0}+$ water. The $\sigma_{\alpha \beta}$ of these three systems are in the following order: $\sigma_{\alpha \beta}\left(n-\mathrm{C}_{4} \mathrm{E}_{0}\right)>\sigma_{\alpha \beta}\left(2-\mathrm{C}_{4} \mathrm{E}_{0}\right)>\sigma_{\alpha \beta}\left(\right.$ iso- $\left.\mathrm{C}_{4} \mathrm{E}_{0}\right)$ at any temperature. That implies $\sigma_{\alpha \beta}$ is predominated by the interaction between hydrophobic alkyl chains. This finding is consistent with that of Yeh et al. ${ }^{17}$ which demonstrated

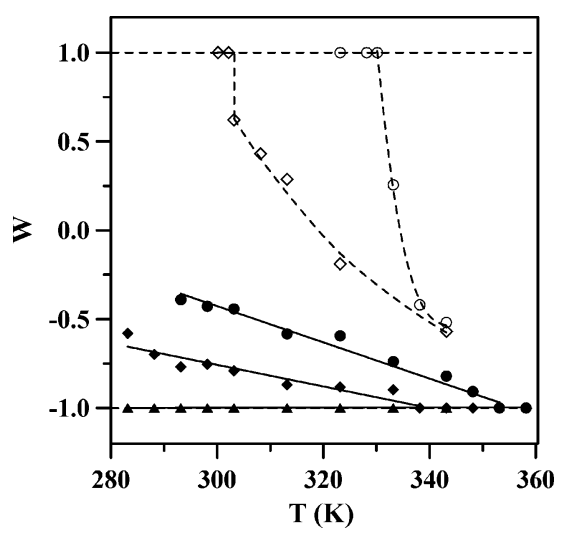

Figure 6. Variation of wetting coefficients as a function of temperature for five water $+\mathrm{C}_{4} \mathrm{E}_{\mathrm{j}}$ systems: $n-\mathrm{C}_{4} \mathrm{E}_{0}(\bullet) ; 2-\mathrm{C}_{4} \mathrm{E}_{0}$ $(\Delta)$; iso- $\mathrm{C}_{4} \mathrm{E}_{0}(\diamond) ; n-\mathrm{C}_{4} \mathrm{E}_{1}(\mathrm{O})$; iso- $\mathrm{C}_{4} \mathrm{E}_{1}(\diamond)$.

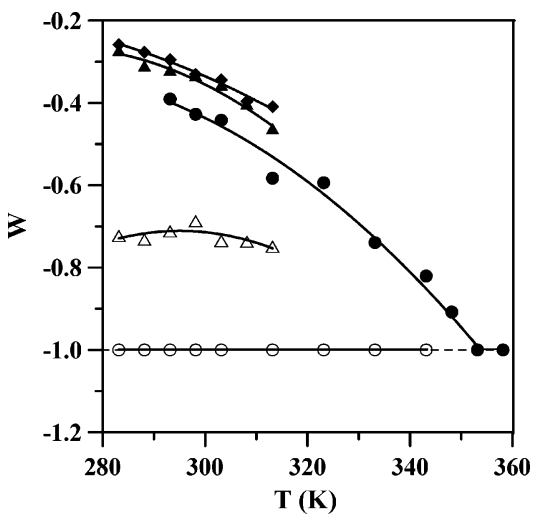

Figure 7. Variation of wetting coefficients as a function of temperature for five water $+\mathrm{C}_{\mathrm{i}} \mathrm{E}_{0}$ systems: $n-\mathrm{C}_{4} \mathrm{E}_{0}(\bullet$, this work); $n-\mathrm{C}_{5} \mathrm{E}_{0}(\Delta) ; n-\mathrm{C}_{6} \mathrm{E}_{0}\left(\diamond\right.$, Yeh et al. $\left.{ }^{17}\right) ; 2-\mathrm{C}_{4} \mathrm{E}_{0}$ (O, this work); and $2-\mathrm{C}_{5} \mathrm{E}_{0}\left(\triangle\right.$, Yeh et al. $\left.{ }^{17}\right)$.

that $\sigma_{\alpha \beta}\left(n-\mathrm{C}_{6} \mathrm{E}_{0}\right)>\sigma_{\alpha \beta}\left(n-\mathrm{C}_{5} \mathrm{E}_{0}\right)>\sigma_{\alpha \beta}\left(n-\mathrm{C}_{4} \mathrm{E}_{0}\right)$ and $\sigma_{\alpha \beta}(n-$ $\left.\mathrm{C}_{5} \mathrm{E}_{0}\right)>\sigma_{\alpha \beta}\left(2-\mathrm{C}_{5} \mathrm{E}_{0}\right)>\sigma_{\alpha \beta}\left(t-\mathrm{C}_{5} \mathrm{E}_{0}\right)$. It was suggested ${ }^{15,16}$ that the longer hydrocarbon chains interact more strongly than the shorter ones in the alcohol-rich phase, and the transfer of alcohol molecules from bulk phase to the airliquid interface is energetically unfavorable for longer chain alcohols. Thus the iso- $\mathrm{C}_{4} \mathrm{E}_{0}+$ water system provides lower surface tension $\sigma_{\alpha \beta}$ due to its shorter "effective" chain length. The same tendency is also observed in the two isomeric $\mathrm{C}_{4} \mathrm{E}_{1}$ systems. That is, $\sigma_{\alpha \beta}\left(n-\mathrm{C}_{4} \mathrm{E}_{1}\right)>\sigma_{\alpha \beta}\left(\right.$ iso- $\left.\mathrm{C}_{4} \mathrm{E}_{1}\right)$.

The homologues series of $n-\mathrm{C}_{i} \mathrm{E}_{0}, n-\mathrm{C}_{4} \mathrm{E}_{0}, n-\mathrm{C}_{5} \mathrm{E}_{0}$, and $n-\mathrm{C}_{6} \mathrm{E}_{0}$, were chosen to examine the influence of alkyl chain length on the wetting behavior of water $+n-\mathrm{C}_{i} \mathrm{E}_{0}$ mixtures. The wetting coefficients as a function of temperature for these three water $+n-\mathrm{C}_{i} \mathrm{E}_{0}$ systems are shown in Figure 7 by filled symbols. The wetting coefficient decreases with rising temperature, as mentioned above, and with decreasing alcohol chain length. This suggests that for water $+\mathrm{C}_{\mathrm{i}} \mathrm{E}_{0}$ systems, the wetting behavior is dominated by the orientation of hydrocarbon chains at the air-water interface. The short-chain alcohol molecules show the usual surface activity and tend to spread over the surface of the aqueous phase. That is, the wetting coefficient increases along with the alcohol chain length. In other words, the wetting behavior of the alcohol-rich phase has a tendency to completely wet the air-water interface when the alcohol chain length decreases at a fixed temperature. This observation can also be predicted by Cahn's critical point wetting theory. Figure 8a schematically shows the liquid-liquid equilibrium phase diagram of three binary systems, $n-\mathrm{C}_{4} \mathrm{E}_{0}+$ water, $n-\mathrm{C}_{5} \mathrm{E}_{0}+$ water, and $n-\mathrm{C}_{6} \mathrm{E}_{0}+$ 


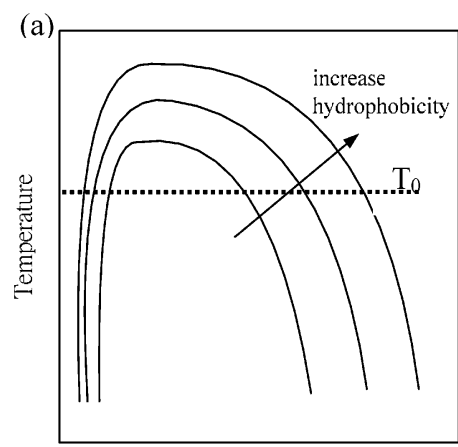

$\mathrm{C}_{\mathrm{j}} \mathrm{E}_{0} \mathrm{wt} \%$

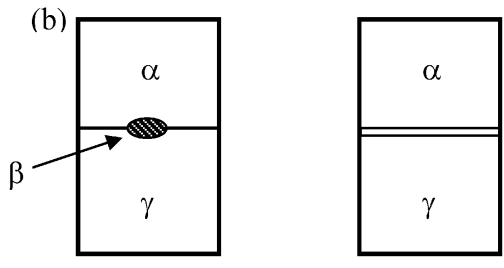

hydrophobicity

Figure 8. Schematic plot of the effect of hydrophobicity for water $+\mathrm{C}_{i} \mathrm{E}_{0}$ binary systems: (a) phase diagram; (b) evolution of the wetting behavior.

water. It is obvious that the upper critical solution temperatures of these three systems are in the order $T_{\mathrm{uc}^{-}}$ $\left(n-\mathrm{C}_{4} \mathrm{E}_{0}\right)<T_{\text {uc }}\left(n-\mathrm{C}_{5} \mathrm{E}_{0}\right)<T_{\text {uc }}\left(n-\mathrm{C}_{6} \mathrm{E}_{0}\right)$. For a given temperature $T_{0}$, as schematically shown in Figure $8 \mathrm{a}$, the temperature difference $\Delta T_{\mathrm{u}}\left(=T_{\mathrm{uc}}-T_{\mathrm{o}}\right)$ for these three systems is also in the order, $\Delta T_{\mathrm{u}}\left(n-\mathrm{C}_{4} \mathrm{E}_{0}\right)<\Delta T_{\mathrm{u}}\left(n-\mathrm{C}_{5} \mathrm{E}_{0}\right)$ $<\Delta T_{\mathrm{u}}\left(n-\mathrm{C}_{6} \mathrm{E}_{0}\right)$. Therefore, switching the system from longchain alcohol to short-chain alcohol at a fixed temperature is equivalent to driving the system to approach the upper critical solution temperature, since $\Delta T_{\mathrm{u}}$ decreases. The critical point wetting theory tells us that a wetting transition from partial wetting to complete wetting must occur when a system is brought to approach its critical point. As a consequence, a partial wetting alcohol-rich phase would tend to completely wet the air-water interface as the alcohol chain length decreases at a fixed temperature, consistent with the prediction of the critical wetting theory.

It is obvious that the hydrophobicity of alcohol increases along with the alcohol chain length. Accordingly, the wetting behavior of the alcohol-rich phase has a tendency to completely wet the air-water interface when the hydrophobicity of alcohol decreases at a fixed temperature. This observation can be further verified by two binary systems, $2-\mathrm{C}_{4} \mathrm{E}_{0}+$ water and $2-\mathrm{C}_{5} \mathrm{E}_{0}+$ water. The wetting coefficients as a function of temperature for these two systems are shown in Figure 7 by open symbols. It was found that the alcohol-rich phase in the system $2-\mathrm{C}_{5} \mathrm{E}_{0}+$ water exhibits partial wetting behavior over the temperature range $10-40{ }^{\circ} \mathrm{C}$. The hydrophobicity of alcohol is decreased by switching alcohol from $2-\mathrm{C}_{5} \mathrm{E}_{0}$ to $2-\mathrm{C}_{4} \mathrm{E}_{0}$. Indeed, the alcohol-rich phase completely wets the airwater interface in the system $2-\mathrm{C}_{4} \mathrm{E}_{0}+$ water, which was observed over the whole experimental temperature range of $10-70{ }^{\circ} \mathrm{C}$. In addition, the critical solution temperature for the system $2-\mathrm{C}_{4} \mathrm{E}_{0}+$ water is lower than that of $2-\mathrm{C}_{5} \mathrm{E}_{0}$ + water. Therefore, changing the system from $2-\mathrm{C}_{5} \mathrm{E}_{0}+$ water to $2-\mathrm{C}_{4} \mathrm{E}_{0}+$ water at a fixed temperature, for example $40{ }^{\circ} \mathrm{C}$, is equivalent to driving the system to approach its critical solution temperature. Again, the

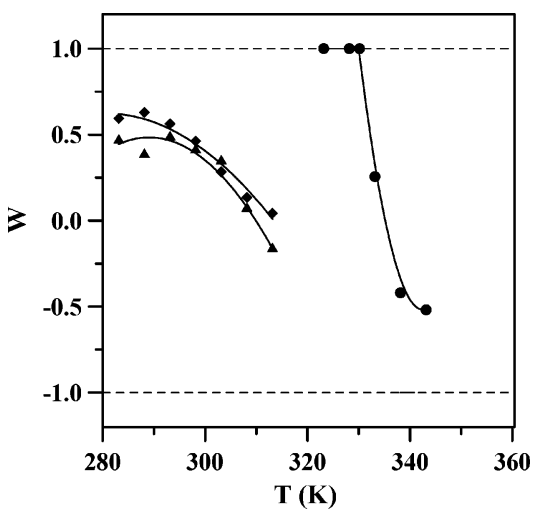

Figure 9. Variation of wetting coefficients as a function of temperature for three water $+\mathrm{C}_{i} \mathrm{E}_{1}$ systems: $n-\mathrm{C}_{4} \mathrm{E}_{1}(\boldsymbol{\bullet}$, this work); $n-\mathrm{C}_{5} \mathrm{E}_{1}(\Delta)$; and $n-\mathrm{C}_{6} \mathrm{E}_{1}\left(\diamond\right.$, Yeh et al. $\left.{ }^{17}\right)$.

alcohol-rich phase would tend to wet the air-water interface with a decrease of the hydrophobicity of alcohol.

The same argument can be applied to two binary systems, $2-\mathrm{C}_{4} \mathrm{E}_{0}+$ water and $n-\mathrm{C}_{4} \mathrm{E}_{0}+$ water. It is obvious that $n-\mathrm{C}_{4} \mathrm{E}_{0}$ is more hydrophobic than $2-\mathrm{C}_{4} \mathrm{E}_{0}$. Indeed, the upper critical solution temperature for the system $2-\mathrm{C}_{4} \mathrm{E}_{0}$ + water $\left(113^{\circ} \mathrm{C}\right)$ is lower than that of $n-\mathrm{C}_{4} \mathrm{E}_{0}+$ water $(125$ $\left.{ }^{\circ} \mathrm{C}\right) .{ }^{44}$ Changing the system from $n-\mathrm{C}_{4} \mathrm{E}_{0}+$ water to $2-\mathrm{C}_{4} \mathrm{E}_{0}$ + water at a fixed temperature, for example $40{ }^{\circ} \mathrm{C}$, is equivalent to driving the system to approach its upper critical solution temperature. Again, the alcohol-rich phase would tend to wet the air-water interface with a decrease of the hydrophobicity of alkyl chain of alcohol, in accord with the prediction of the critical wetting theory.

According to the wetting coefficients shown in Figure 6 , the order of the wetting transition between partial wetting and complete wetting is hard to identify. Currently, we are in the process of using ellipsometry to identify the order of transition.

To summarize the experimental evidence, the evolution of wetting behavior of the $\mathrm{C}_{i} \mathrm{E}_{j}$-rich phase in water $+\mathrm{C}_{i} \mathrm{E}_{j}$ systems near their upper critical solution temperatures as a function of the hydrophobicity of alcohol can be generally described in Figure $8 b$.

Effect of Hydrophobicity of $\mathrm{C}_{i} \mathrm{E}_{j}$ on Wetting Behavior Approaching the Lower Critical Solution Temperature. We would like to further discuss the tendency of wetting behavior in three systems, $n-\mathrm{C}_{4} \mathrm{E}_{1}+$ water, $n-\mathrm{C}_{5} \mathrm{E}_{1}+$ water, and $n-\mathrm{C}_{6} \mathrm{E}_{1}+$ water, as a function of the hydrophobicity of the alkyl chain of alcohol near their lower critical solution temperatures. The wetting coefficients as a function of temperature for these three systems are shown in Figure 9. These three systems exhibit liquid-liquid equilibrium over our experimental temperature range of $10-80{ }^{\circ} \mathrm{C}$. There exists a lower critical solution temperature $T_{\mathrm{lc}}\left(=49^{\circ} \mathrm{C}\right)$ for the $n-\mathrm{C}_{4} \mathrm{E}_{1}+$ water system. In the other two systems, the miscibility gaps extend below the freezing temperature. Whether the two liquid phases of the miscibility gap merge with a lower critical end point has not been experimentally verified in these two systems. The lower critical solution temperatures of these three systems, if they exist, are in the order, $T_{\mathrm{lc}}\left(n-\mathrm{C}_{4} \mathrm{E}_{1}\right)>T_{\mathrm{lc}}\left(n-\mathrm{C}_{5} \mathrm{E}_{1}\right)>T_{\mathrm{lc}}\left(n-\mathrm{C}_{6} \mathrm{E}_{1}\right)$. The schematic phase diagram of these three systems is shown in Figure 10a. The mutual solubility of $\mathrm{C}_{i} \mathrm{E}_{j}$ and water increases along with the hydrophilicity of $\mathrm{C}_{i} \mathrm{E}_{j}$. Therefore, the solubility envelope shrinks and moves upward when the hydrophilicity of alcohol increases. For a given temperature $T_{0}$, as shown in Figure 10a, the temperature difference $\Delta T_{1}\left(=T_{\mathrm{o}}-T_{\mathrm{lc}}\right)$ for these three systems is also in the order $\Delta T_{1}\left(n-\mathrm{C}_{4} \mathrm{E}_{1}\right)<\Delta T_{1}\left(n-\mathrm{C}_{5} \mathrm{E}_{1}\right)<\Delta T_{1}\left(n-\mathrm{C}_{6} \mathrm{E}_{1}\right)$. 

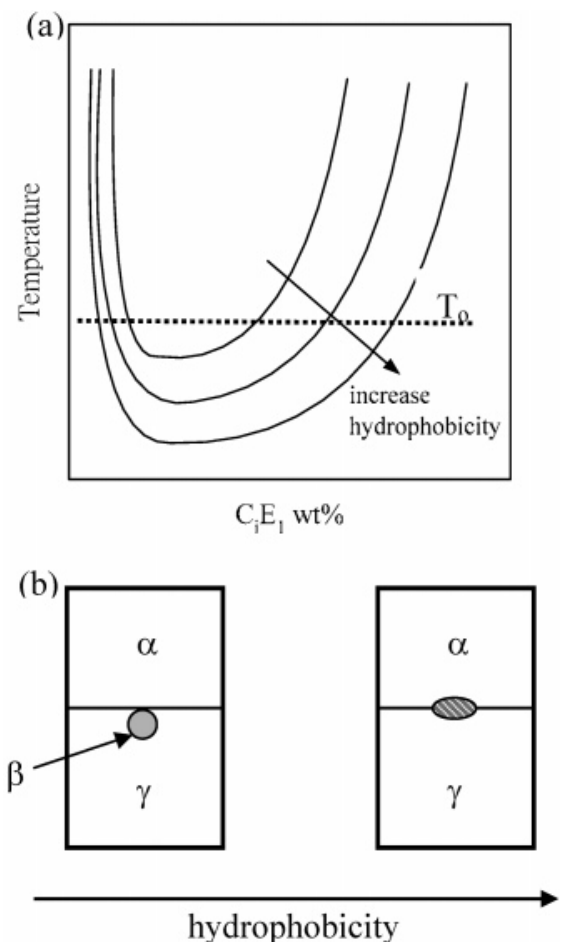

hydrophobicity

Figure 10. Schematic plot of the effect of hydrophobicity for water $+\mathrm{C}_{i} \mathrm{E}_{1}$ binary systems: (a) phase diagram; (b) evolution of the wetting behavior.

Therefore, switching the system from a long-chain alcohol to a short-chain alcohol at a fixed temperature and at a fixed number of oxyethylene headgroups is equivalent to driving the system to approach its lower critical solution temperature, since $\Delta T_{1}$ decreases. The critical point wetting theory tells us that a wetting transition from partial wetting to complete wetting must occur when a system is brought to approach its critical point. As a consequence, a partial wetting alcohol-rich phase would tend to de-wet the air-water interface as the alcohol chain length decreases at a fixed temperature. That is, a partial wetting aqueous phase would tend to completely wet the interface separating air and alcohol-rich phases as the alcohol chain length decreases at a fixed temperature and a fixed number of oxyethylene headgroups, obviously consistent with the prediction of the critical wetting theory.

The hydrophobicity of $\mathrm{C}_{i} \mathrm{E}_{j}$ is adjustable by tuning either the alkyl chain length $i$ or the number of oxyethylene groups $j$. The homologues series of $\mathrm{C}_{4} \mathrm{E}_{j}, \mathrm{C}_{4} \mathrm{E}_{0}$ and $\mathrm{C}_{4} \mathrm{E}_{1}$, were chosen to examine the influence of the number of oxyethylene groups on the wetting behavior of water + $\mathrm{C}_{4} \mathrm{E}_{\mathrm{j}}$ mixtures. The effect of the oxyethylene groups on the wetting coefficient is shown in Figure 6. The wetting coefficient increases with an increase in the number of oxyethylene groups $j$, consistent with Kahlweit and Busse's conjecture $^{1}$ and the experimental finding of Yeh et al. ${ }^{17}$ At a constant temperature of $323.15 \mathrm{~K}$, the wetting coefficient evolves from -0.594 to +1 as the number of oxyethylene groups $j$ increases from 0 to 1 . That is, a wetting transition from partial wetting to nonwetting is observed in the water $+\mathrm{C}_{4} \mathrm{E}_{\mathrm{j}}$ system by varying the number of oxyethylene groups from 0 to 1 . The mutual solubility of $\mathrm{C}_{4} \mathrm{E}_{j}$ and water increases along with an increase in the number of oxyethylene groups $j$. Thus, the solubility envelope shrinks and moves upward when the number of oxyethylene groups $j$ increases, as schematically illustrated in Figure 10a. For a given temperature $T_{0}$, as shown in Figure 10a, the temperature differences $\Delta T_{1}\left(=T_{\mathrm{o}}\right.$ $\left.-T_{\text {lc }}\right)$ for these two systems are in the order, $\Delta T_{1}\left(n-\mathrm{C}_{4} \mathrm{E}_{0}\right)$
$>\Delta T_{1}\left(n-\mathrm{C}_{4} \mathrm{E}_{1}\right)$. Therefore, switching the system from $j=$ 0 to $j=1$ at a fixed temperature is equivalent to driving the system to approach its lower critical solution temperature, since $\Delta T_{1}$ decreases. The critical point wetting theory tells us that a wetting transition must occur when a system is brought to approach its critical point. Indeed, a wetting transition from partial wetting to nonwetting is observed. The same tendency of wetting behavior of the alcohol-rich phase in water $+\mathrm{C}_{\mathrm{i}} \mathrm{E}_{\mathrm{j}}$ systems was observed in another homologues series of $\mathrm{C}_{6} \mathrm{E}_{j}: \mathrm{C}_{6} \mathrm{E}_{0}, \mathrm{C}_{6} \mathrm{E}_{1}$, and $\mathrm{C}_{6} \mathrm{E}_{2} \cdot{ }^{17}$

According to the wetting coefficients shown in Figure 6 , the wetting transition between partial wetting and nonwetting is a first-order transition, consistent with previous experimental results ${ }^{30}$ as well as with the theoretical predicition. ${ }^{47,48}$ Currently, we are in the process of using an ellipsometry to further verify this finding. Note that a hysteresis of the thickness of a wetting layer was found in the cyclohexane + methanol system, ${ }^{32}$ consistent with the assumption of a first-order transition.

To summarize the experimental evidence, the evolution of the wetting behavior of the $\mathrm{C}_{i} \mathrm{E}_{j}$-rich phase in water + $\mathrm{C}_{i} \mathrm{E}_{j}$ systems near their lower critical solution temperatures as a function of the hydrophobicity of alcohol can be generally described in Figure 10b.

\section{Conclusion}

In this study, a pendant drop/bubble tensiometer was assembled for surface/interfacial tension measurements over the temperature range from 10 to $85^{\circ} \mathrm{C}$. We performed the surface/interfacial tension for five binary systems: (1) water $+n-\mathrm{C}_{4} \mathrm{E}_{0},(2)$ water $+2-\mathrm{C}_{4} \mathrm{E}_{0},(3)$ water + iso- $\mathrm{C}_{4} \mathrm{E}_{0}$, (4) water $+n-\mathrm{C}_{4} \mathrm{E}_{1}$, and (5) water + iso- $\mathrm{C}_{4} \mathrm{E}_{1}$. The experimental data of these five mixtures along with another eight binary water $+\mathrm{C}_{i} \mathrm{E}_{j}$ systems ${ }^{17}$ were used to systematically examine the wetting behavior of the $\mathrm{C}_{i} \mathrm{E}_{j^{-}}$ rich phase at the interface separating air and the aqueous phase.

For all the binary water $+\mathrm{C}_{i} \mathrm{E}_{j}$ mixtures, to start with a partial wetting $\mathrm{C}_{i} \mathrm{E}_{j}$-rich phase, a wetting transition from partial wetting to complete wetting is always observed when the system is brought to close to its upper critical solution temperature. There exists a lower critical solution temperature for some mixtures, for example, water + $n-\mathrm{C}_{6} \mathrm{E}_{2}$, water $+n-\mathrm{C}_{4} \mathrm{E}_{1}$, and water + iso- $\mathrm{C}_{4} \mathrm{E}_{1}$. A wetting transition from partial wetting to nonwetting is always observed when the system is driven to approach to its lower critical solution temperature.

The effect of hydrophobicity of $\mathrm{C}_{i} \mathrm{E}_{j}$ on the wetting behavior near the upper critical solution temperature is summarized by Figure 8. An increase in the hydrophobicity of $\mathrm{C}_{i} \mathrm{E}_{j}$ at a fixed temperature $T_{\mathrm{o}}$ would bring the system further away from its upper critical end point, as schematically illustrated in Figure $8 \mathrm{a}$. As a consequence, a wetting transition from partial wetting to complete wetting must occur when the hydrophobicity of $\mathrm{C}_{i} \mathrm{E}_{j}$ in the binary water $+\mathrm{C}_{i} \mathrm{E}_{j}$ system is diminished, as illustrated in Figure 8b. On the other hand, the effect of hydrophobicity of $\mathrm{C}_{i} \mathrm{E}_{j}$ on the wetting behavior near the lower critical solution temperature is summarized by Figure 10. A decrease in the hydrophobicity of $\mathrm{C}_{i} \mathrm{E}_{j}$ at a fixed temperature $T_{\mathrm{o}}$ would bring the system close to its lower critical end point, as schematically illustrated in Figure 10a. Consequently, a wetting transition from partial wetting to nonwetting must occur when the

(47) Yeh, M.-C.; Chen, L.-J. J. Chem. Phys. 2003, 118, 8331.

(48) Yeh, M.-C.; Chen, C.-M.; Chen, L.-J. J. Phys. Chem. B 2004, 108,7271 . 
hydrophobicity of $\mathrm{C}_{i} \mathrm{E}_{j}$ in the binary water $+\mathrm{C}_{i} \mathrm{E}_{j}$ system is reduced, as illustrated in Figure 10b. As a conclusion, an increase in the hydrophobicity of $\mathrm{C}_{i} \mathrm{E}_{j}$ in the binary water $+\mathrm{C}_{i} \mathrm{E}_{j}$ system would induce the $\mathrm{C}_{i} \mathrm{E}_{j}$-rich phase to exhibit a wetting transition from complete wetting (or nonwetting) to partial wetting at the interface separating air and the aqueous phase.
Acknowledgment. We thank Professor Ming-Jer Lee of National Taiwan University of Science and Technology for the help in assembling the apparatus. This work was supported by the National Science Council of Taiwan, Republic of China.

LA050691I 